\title{
Study on Landscape Design of Horticulture Industry Park based on Modern Agriculture
}

\author{
Xin Liu \\ Kunming University, Kunming, Yunnan, 650241
}

Keywords: Modern Agriculture, Horticultural Industry, Park Landscape.

\begin{abstract}
With the development of economy, horticulture industry is also developing. Park landscape is designed to beautify the surrounding environment, an important means to enhance the natural scenery. Based on the concept of modern agriculture, the landscape design of the horticultural industry park should first investigate the present situation of the landscape. Secondly, the theme of landscape design should be clarified. Finally, according to the actual situation of the landscape and the design theme, the landscape of the park is designed according to the contemporary style and theme. In this paper, the landscape of modern agricultural park is summarized, and then the design concept and characteristics of modern agriculture park are analyzed. The landscape design of horticultural industry park based on modern agriculture concept is studied for reference.
\end{abstract}

\section{Introduction}

In the 1990s, with the development of the national economy, China's agricultural modernization in the emergence of a variety of functions in one of the new agricultural development model - the modern agricultural park. The emergence of modern agricultural park, to promote China's modernization and agricultural modernization, is the organic combination of modern science and technology and agriculture. The construction of modern agricultural park symbolizes the rapid discovery of agricultural economy, science and technology and knowledge popular education in our country, which affects the atmosphere and style of contemporary economic construction in a certain extent. Therefore, the agricultural landscape design is particularly important, landscape quality and overall planning of the agricultural park image and healthy development of a huge impact. In the park construction, emphasizing the modern agriculture industrial park landscape construction is the focus of landscape design.

\section{Overview of modern agriculture park landscape}

As the animal, natural plants, industrial facilities, construction, water, rocks, crops and other elements of the complex is the modern agricultural park landscape [1]. The fusion of different elements can constitute a completely different combination of results for visitors to provide a beautiful viewing environment. Technology-intensive is the main feature of modern agricultural park, promotion, radiation, demonstration and science and technology development is the main content of modern agricultural park, "benefit sharing, risk sharing" is the principle of modern agricultural park. Modern agriculture parks have played a typical demonstration role of traditional agriculture to modern agriculture. It is the display window of modern agriculture. It is also the key to improve the modern management level and high-tech content of modern agricultural park and promote the development of agricultural science and technology.

Modern agriculture park landscape reflects the unique charm of modern agriculture is the key, but also highlights the focus of agricultural landscape personality [2]. Comprehensive analysis found that the characteristics of modern agricultural park landscape mainly as follows: First, the theme of the. The theme is the core of the modern agricultural park landscape, but also the soul of the development of agricultural parks. At present, the modern agricultural park landscape landmark 
theme is the agricultural landscape and agricultural production. In the modern agricultural park landscape theme and the third industry factor effectively combined. At the same time, it will promote the development of economic and entertainment as the goal, to the characteristics of the characteristics of agricultural aesthetics to develop, so as to promote the development of agricultural economy, and further improve the efficiency of modern agricultural park landscape development. Second, regional. China's vast land, different regions of the ecological environment, climate factors are not the same, natural resources and industry naturally not the same. Therefore, in the modern agricultural park landscape transformation and design, should fully follow the local characteristics, highlighting the unique charm of the local, so that people find the glittering point of agricultural landscape, and can not be stereotyped, hinder the development of modern agriculture. Third, service. The main purpose of the modern agricultural landscape is to make people better enjoy the natural scenery, enjoy the pastoral life, enrich people's spiritual and cultural life. Therefore, the construction of modern agricultural landscape, should fully demonstrate the service, for the agricultural landscape shape, area, continuity, proportion, spatial structure and so do the corresponding planning.

\section{Modern agriculture park landscape design concept and transformation points}

Want to do a good job of modern agricultural park landscape design, we should first understand the modern agricultural park landscape design concept. First, focus on the park as a whole landscape theme to create [3]. The so-called overall sense of the agricultural park is the overall style, and now the agricultural park landscape design, some designers in order to highlight the beauty of the individual landscape and ignore the whole, resulting in individual landscape although unique, but the lack of unity. Therefore, in the modern agricultural park landscape design concept, the designer should adhere to the park theme of the overall landscape to create. Second, focus on regional characteristics. In different areas of natural conditions and regional culture are not the same, in the modern agricultural park landscape design, designers should be local conditions, combined with the local geographical characteristics, the rich humanities into one, so that it has a distinctive geographical characteristics and rich Connotation. Third, highlight the landscape axis design. In general, the modern agricultural park design range is relatively wide, involving more factors. Designers can be through the landscape axis, the first of the backbone of the agricultural park structure, and then do the overall convergence and landmark landscape axis planning, the area of the tour route carefully designed and planned. Fourth, highlight the design of landscape nodes. Modern agriculture park landscape design is not only to highlight the theme and the whole, but also highlight the landmark landscape nodes. Building a good iconic landscape node, can be more attractive to the reader's eyes.

Modern agriculture park landscape transformation needs the main points include: First, functional integrity. Functional integrity includes complete park service facilities, green ecosystem integrity, complete road system, etc. [4]. Designers to ensure the integrity of the park on the basis of the function, but also can enhance the connotation of the park. Second, species diversity. Unlike other landscape construction, the agricultural park involves relatively few factors. In the construction of agricultural parks, should not be in pursuit of landscape characteristics of the prominent, and destroy the diversity of local species. Rich dynamic, plant varieties, highlight the level and quality, to protect the local ecological environment are modern agricultural park landscape transformation of the main points. In the transformation of agricultural landscape, it should be combined with the characteristics of the local landscape, the customs into the landscape design, highlighting the characteristics of landscape design.

\section{Modern agriculture concept of horticultural industrial park landscape design}

In the design of modern agricultural park landscape design, we should first investigate and analyze the characteristics of the local park landscape, find out the existing problems in the park landscape, and then combined with the transformation of the theme and the existing landscape 
problems in the design [5] The Generally speaking, the traditional park landscape in the following problems: First, the landscape quality is low. Traditional garden landscape, plant varieties vary, variety and style of a single, while landscape design is not a sense of hierarchy, diversity is relatively poor [6]. In addition, due to the lack of scientific design and management, many places the phenomenon of plant dying, leading to large tracts of soil exposed, affecting the landscape quality of the park. Second, the regional characteristics are not prominent. Traditional garden landscape design into the local landscape factors less, mainly to the main flowers and trees, resulting in stereotyped situation, geographical features are not prominent. Third, the landscape is not in the theme. Traditional park landscape construction, there is no theme of landscape construction planning, resulting in the park landscape and horticultural industrial park theme does not match, affecting the development of horticultural industry.

After collecting the basic situation of the park landscape, the designer should be based on the traditional landscape problems, the park landscape design. First, the overall upgrade design [7]. In general, the modern agricultural park landscape volume is large, in the transformation of the design, it should be from the park status, function, design theme and other overall point of view, the park landscape according to different functions of the district, give full play to the main agricultural Features. Second, the axis to enhance the design. The axis is the key to connecting the various branches of the agricultural park, with visual core and visual guidance function, which can connect the environment, grade, image and so on of the agricultural park. Therefore, the designer in the transformation of the park landscape, should make full use of the axis function, the use of axis transformation design. At the same time, from the ecological point of view, the environmental protection and species diversity principles into which, combined with lawns, low shrubs, etc., in the park landscape to establish a "green axis" features. The use of visual permeability, large color blocks, vegetation shaping streamlined, etc., the landscape "green axis" in the end [8]. In the modern agricultural park landscape design, in addition to the need to focus on the whole, but also need to create local characteristics. The use of landmark landscape nodes can effectively highlight the local characteristics, attract more tourists. In general, the characteristics of economic forest display area, eco-landscape landscape area and the land of new varieties of horticultural display area is the choice of most people, therefore, designers in the transformation, you can combine the local characteristics of the theme, highlight the species Diversity, economic conservation, regional characteristics and the theme of the concept, to create a landmark landscape nodes. For different viewing areas, designers should fully grasp the characteristics of the viewing area. For example, in the ecological garden browsing area, select the plant, you can salt, sand and other characteristics of the main plant, highlighting the regional characteristics. And in the characteristics of economic forest display area can be the local characteristics of agricultural economic plants as the main ornamental plants, while the integration of agricultural park theme, regional characteristics and popular science features. Fourth, plant upgrading design. Modern agriculture park landscape in the preparation of the whole plant, should fully follow the relevant principles, to retain the original vegetation and increase the characteristics of famous plants. In the traditional landscape design of the park, there are usually a single landscape, ecological benefits are not significant and so on, therefore, in the transformation of the local agricultural park landscape, it should highlight the local characteristics, the local famous plants into the landscape design, the formation of rich layers, species diversity, And the plant community.

\section{Conclusion}

In summary, with the development of agricultural economy, the development of modern agricultural landscape to promote the development of tourism economy, to protect the local ecological environment, an important means to improve species diversity. Therefore, in the landscape design transformation, should fully understand the original landscape characteristics, combined with the theme of agricultural development, into more local elements, so that agricultural landscape more regional characteristics, so as to attract more tourists. 


\section{References}

[1] Yang Le. Study on Planning of Eco-agroforestry Based on Low-carbon-Recycling Agriculture [J]; Journal of Central South University of Forestry and Technology; 2012.

[2] Su Shengli.Study on the Planning Method of Agricultural Ecological Park Based on Landscape Morphology-Taking Ma'anshan Agricultural Ecological Park as an Example [D]. Hefei University of Technology, 2015

[3] Zhang Ying. Modern agriculture garden landscape and CIS identification - Taking Jiangsu Zhongyang Ecological Agriculture Industrial Park as an example [D]. Nanjing Agricultural University, 2013

[4] Kummerling, M., Muller, N. The relationship between landscape design style and the conservation value of parks: a case study of a historical park in Weimar, Germany. [J]. Landscape and Urban Planning, 2012, 107 (2): 111-117.

[5] Yang Zhiwen. Leisure agriculture garden in the application of horticultural function research Chizhou "Qingfeng rain leisure agriculture garden" as an example [D]. Anhui Agricultural University, 2016

[6] Yuan Yajing. Tourism Agriculture Park landscape ecological design method research [D]. Anhui Agricultural University, 2012.

[7] Hobinger, T., Schindler, S., Seaman, BS et al. Impact of oil palm plantations on the structure of the agroforestry mosaic of La Gamba, southern Costa Rica: potential implications for biodiversity. (Special Issue: Agroforestry landscapes. [J] .Agroforestry Systems, 2012, 85 (3): 367-381.

[8] Feng Peiyuan. Planning and Exploration of Urban Agricultural Park - Taking Zhangjiagang Daxin Agricultural Park as an Example [D].Nanjing Agricultural University, 2014. 